\title{
A MULTI-SCALE MODELLING APPROACH PREDICTING THE EFFECT OF POROSITY ON THE TRANSVERSE STRENGTH IN COMPOSITES
}

\author{
B. Fisher $^{1 *}$, M. Eaton ${ }^{1}$, R. Pullin ${ }^{1}$ \\ ${ }^{1}$ School of Engineering, Cardiff University, Cardiff, UK \\ *fisherb2@cardiff.ac.uk
}

\section{Introduction}

Composite materials often have manufacturing defects, such as voids [1], meaning tools like numerical modelling can be used to address the uncertainty. The approach presented here is evolved from the current modelling strategies, such as those performed by Nikopour [2] and Jaing et al. [3] by accounting for realistic void generation.

\section{Model Description}

The first stage is a microscale model which homogenises the impact of voids in neat resin. The calculated material properties are passed through to the mesoscale model by situating the fibres within the homogenised matrix. The updated model is loaded until failure at which point ply level strengths can be predicted ready to be used in component design.

\section{Experimental Validation}

To validate the model, laminates with differing porosity were manufactured. Specimens were subjected to compressive testing and found to have a $10.5 \%$ reduction in strength. Microscopy was used to generate unit cells and the modelling process described in Section 2 was followed providing a model correlation of over 95.2\%. The experimental and modelling results can be seen in Figure. 1. Once validated, the model was used to show a reduction in tensile strength from $60.5 \mathrm{MPa}$ to $50.6 \mathrm{MPa}$.

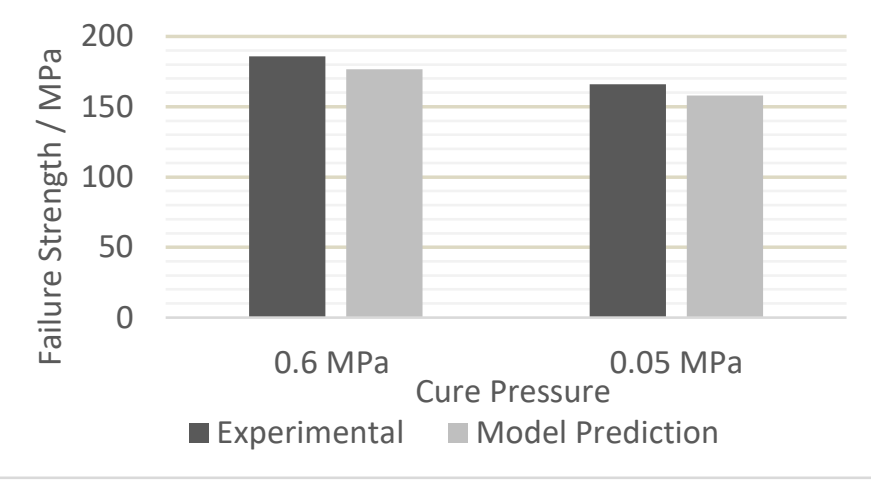

Figure. 1. Experimental and model prediction of transverse compressive strength of laminates cured at $0.6 \mathrm{MPa}$ and $0.05 \mathrm{MPa}$.

\section{Conclusion}

A multi-scale model has been developed and validated to predict the transverse strengths of composites with varying porosity. The microscale model predicts the homogenised matrix strength due to voids and this result is then used in a mesoscale model to predict the knocked down transverse ply strengths. The approach was validated with a correlation of over $95.2 \%$.

\section{References}

[1] Talreja. R "Manufacturing defects in composites and their effects on performance". In: P. Irving and C. Soutis "Polymer composites in the aerospace industry". 2nd edition, Elsevier Ltd, 2020.

[2] Nikopour. H "A virtual frame work for predication of effect of voids on transverse elasticity of a unidirectionally reinforced composite". Computational Materials Science, Vol. 79, pp 25-30, 2013.

[3] Jiang. H, Ren. Y, Liu. Z, et al. "Microscale finite element analysis for predicting effects of air voids on mechanical properties of single fiber bundle in composites". Journal of Materials Science, Vol. 54, pp 1363-1381, 2019. 